\title{
REFORMA TRABALHISTA E SUAS IMPLICAÇÕES NO ACESSO À JUSTIÇA: UMA PERSPECTIVA DA PESQUISA EMPÍRICA EM DIREITO'
}

Ana Flávia de Moraes Toller² Alexandre dos Santos Cunha ${ }^{3}$ Paulo Eduardo Alves da Silva ${ }^{4}$

Danielle Zoega Rosim ${ }^{5}$

Victor Dantas de Maio Martinez ${ }^{6}$

\section{REFORMA TRABALHISTA: FUNDAMENTOS E ASPECTOS LEGISLATIVOS}

Em dezembro 2016 foi apresentado à Câmara dos Deputados o Projeto de Lei no 6.787, com objetivo de alterar dispositivos da Consolidação das Leis do Trabalho (CLT) de 1943. Sua justificativa genérica era a necessidade de aprimorar as relaçôes trabalhistas no Brasil, pois a legislação estaria ultrapassada.

Especificamente, alertava para uma necessidade de tratar com maior paridade as relaçóes entre trabalhadores e empregadores, pelo fomento à prática de acordos coletivos e individuais diretos entre os dois polos da relaçáo trabalhista. Ademais, defendia a imprescindibilidade de uma reforma para desafogar a Justiça do Trabalho, cujo alto volume de processos resultaria de um tipo de litigância passível de ser resolvida extrajudicialmente, por meio de acordos de verbas rescisórias, por exemplo (Brasil, 2016, p. 8).

Sabe-se, no entanto, que desde 1990 existe um contínuo aprimoramento de medidas que visam desregulamentar direitos e flexibilizar relaçóes de trabalho (Krein, 2003, p. 272). Elas pretenderam inserir o Brasil no mercado mundial durante um processo intenso de globalização, circulação financeira, desobstrução ao mercado internacional, privatização e estabilização monetária. Esse conjunto de razóes inflamou o discurso da necessidade de reformular contratos de trabalho perante o novo mercado, verdadeiro clamor por isonomia entre as partes no contrato empregatício e autonomia do trabalhador (Antunes, Oliveira e Ferrer, 2019, p. 2077).

As ideias sustentadas pelo projeto de reforma trabalhista no Brasil seguem a linha do Nobel de Economia Jean Tirole (2017), o qual considera imprescindível uma reforma que flexibilize a contratação e dispensa de trabalhadores, diminua o elevado custo de suas garantias amplas

1. DOI: http://dx.doi.org/10.38116/bmt70/pfa2

2. Auxiliar de pesquisa do Subprograma de Pesquisa para o Desenvolvimento Nacional (PNPD) na Diretoria de Estudos e Políticas do Estado, das Instituições e da Democracia (Diest) do Ipea. E-mail: <ana.toller@ipea.gov.br>.

3. Coordenador de Estudos sobre Estado e Democracia (Codem) na Diest//pea.E-mail: <alexandre.cunha@ipea.gov.br>.

4. Professor da Universidade de São Paulo (USP). Pesquisador visitante na Diest/lpea.E-mail: <pauloeduardoalves@usp.br>.

5. Assistente de pesquisa do PNPD/Diest//pea.E-mail:<danielle.rosim@ipea.gov.br>.

6. Auxiliar de pesquisa do PNPD/Diest//pea.E-mail: <victor.martinez@ipea.gov.br>. 
e de estabilidade empregatícia, responsáveis por prejudicar empresários, resvalando em maior mecanização, menor contratação de trabalhadores e ensejando crescente desemprego. Para o autor, portanto, o protecionismo náo resolve a falta de empregos, mas a agrava.

Do projeto da Câmara dos Deputados, nasceu a Lei no 13.467, de 13 de julho de 2017 (Brasil, 2017), conhecida como Lei da Reforma Trabalhista. Em seu bojo, reforçou vários dos ideais defendidos no projeto de lei (PL) original, e trouxe outros pontos inéditos para discussão. Importa, para este artigo, no entanto, focalizar quais das suas sensíveis alteraçóes materiais e processuais, vigentes desde novembro de 2017, impactaram no acesso à justiça e de que modo confirmam ou refutam as hipóteses trazidas no discurso parlamentar e dos membros do Judiciário brasileiro.

Tal discurso, inclusive, foi reiterado por Ives Gandra Martins Filho, presidente do Tribunal Superior do Trabalho (TST) à época da promulgação da Lei da Reforma Trabalhista. Ele apontou que a reforma estaria no rumo certo, ao estimular negociação coletiva e dar autonomia dos agentes econômicos para estabelecimento de regras e condiçóes de trabalho. Afinal, traria maior segurança aos dois polos da relação trabalhista (Martins Filho, 2019).

Assim, muito se discute quanto às intençóes e efeitos da reforma e existem opinióes que apontam para um caminho nefasto dessas alteraçóes na vida dos trabalhadores brasileiros. De fato, a reforma trabalhista incide sobre o direito material e processual, tornando-se potencial força motriz da modificação nas relaçóes entre o autor do processo trabalhista, o réu e o acesso à justiça. Por isso, parte considerável da doutrina, pesquisadores e magistrados, defende que a reforma prejudica garantias constitucionais de acesso ao atingir direitos conquistados.

Por seu turno, quem apoia a reforma, considera que seu objetivo é alterar o anacronismo da legislação trabalhista, ao eliminar a tendência do Judiciário de criar novos direitos pautado em princípios genéricos de baixa densidade normativa, como o da dignidade da pessoa humana. Estes também sustentam que ela nasceu para fortalecer o mercado de trabalho por meio da flexibilização de direitos, deveres e garantia novos parâmetros de acesso ao Judiciário. A reforma se traduz, nesse sentido, como meio de se possibilitar um formato de calculabilidade do funcionamento do processo jurídico, capaz de fortalecer empresas econômicas, estabilizá-las e garantir sua segurança jurídica (Weber, 2011, p. 281).

\section{ACESSO À JUSTIÇA}

O conceito de acesso à justiça perfila debates teóricos até hoje não pacificados. É consenso, no entanto, que não se limita a um direito formal de acessar a jurisdição. A referência mais sedimentada é a proposta por Cappelletti e Garth (1988). Para os autores, acesso é a efetiva assistência jurídica (conhecida por primeira onda), representaçáo e proteçáo a interesses difusos e coletivos (segunda onda) e procedimentos diferenciados conforme as distintas lides (terceira onda). Além disso, Cappelletti e Garth (1988, p. 9) entendem que, para sua garantia, o Estado precisa atuar positivamente. 
Por sua vez, Rebecca Sandefur (2009) divide as abordagens de acesso à justiça entre comportamentais e perceptivas. Aquelas se referem ao funcionamento dos órgãos e estas aos comportamentos dos atores envolvidos ou às suas percepçôes de justiça. Ou seja, pode ser tratada pela perspectiva do sistema de justiça (performance dos atores institucionais, eficiência dos órgãos e racionalidade dos procedimento) "de cima para baixo" ou pelo viés da sociedade civil (capacidade dos indivíduos, grupos sociais e empresas em relação aos seus direito), de "baixo para cima".

A pesquisa que será utilizada neste artigo visou analisar o acesso por essas últimas duas perspectivas, de forma a avaliar qual o nível de conformidade entre as intençóes da Lei n⿳o 13.467/2017 e a prática da litigância trabalhista, além de verificar se elas se confirmam ou refutam após quase três anos do início da vigência da nova legislação.

\section{OS DADOS ANALISADOS}

Os dados utilizados para análise são os resultantes da pesquisa Seleção e Recrutamento de Magistrados e Acesso à Justiça do Trabalho, realizada durante o ano de 2019 pelo Ipea, vinculado ao Ministério da Economia (ME), em conjunto com a Escola Nacional de Formação e Aperfeiçoamento de Magistrados do Trabalho (Enamat), vinculada ao TST, no âmbito do Termo de Execução Descentralizada, firmado entre ambas organizaçóes em fevereiro de 2019.

Com base em pesquisa empírica, viabilizada pela análise de autos findos registrados como sentenciados no sistema judiciário no ano de 2018, foi possível selecionar aspectos da litigância trabalhista para que fossem comparados a dados de pesquisa símile do ano de 2012. ${ }^{7}$ Assim, o processamento desses dados consolidados permitiu desenhar hipóteses a respeito dos efeitos dessa nova legislaçáo na prática judiciária, respondendo qual o perfil do litigante trabalhista, que demandas tem apresentado e quais respostas tem recebido.

Para realizar a pesquisa, foi utilizado instrumento de coleta de dados virtual com perguntas sobre o perfil do autor, o tipo de vínculo da relação de trabalho, o setor econômico das partes, as pretensóes deduzidas pelo(a) autor(a), a taxa de sucesso da açáo, o valor médio das condenaçóes e a taxa de cumprimento da sentença ou o valor médio efetivamente pago como resultado de uma decisão favorável.

A amostra processual resultou em um banco de dados com informaçóes sobre 981 processos, que tramitaram em 319 cidades diferentes, nas 24 regiōes da Justiça do Trabalho. Ela foi composta por processos propostos antes (48\% dos autos) e depois (53\% dos autos) da reforma trabalhista. A análise de processos propostos antes da vigência da reforma foi essencial, pois processos iniciados após novembro de 2017 e sentenciados em 2018 são, no geral, processos mais simples, os quais não possibilitariam uma pesquisa mais densa como a proposta.

7. Em 2012, por meio de Acordo de Cooperação Técnica, firmado com o Conselho Superior da Justiça do Trabalho (CSIT), foram levantados dados completos de uma amostra nacional de quase 9 mil processos trabalhistas que haviam concluído tramitação em todas as varas do trabalho do país. O levantamento deu base à elaboração e disponibilização pública de um Banco Nacional de Autos Findos de Ações Trabalhistas (Banafat). 


\section{RESULTADOS DA PESQUISA}

Nesta seção serão destacados alguns pontos sensíveis da coleta, cuja interpretação permeia aspectos da reforma trabalhista, confirmando ou refutando suas premissas.

\subsection{Perfil dos atores processuais}

Conforme divulgado pela opinião pública no bojo argumentativo da reforma, a pesquisa confirmou que a relação processual trabalhista é homogênea. Em 71,46\% dos processos analisados estavam presentes um autor e um réu. Esse panorama confirma tendência de litigância, na qual o polo ativo processual é representado pelo trabalhador, pessoa física $(92,1 \%)$, e o polo passivo, o réu empregador, pessoa jurídica de direito privado (81,7\%). Aliás, o polo ativo da relação jurídica de 2012 para 2018 não contou com alteraçôes percentuais significativas, pois, em 2012, 93,3\% dos autores eram pessoas físicas.

Saliente-se, no entanto, que ao contrário do sustentado nas razóes da reforma, a litigância não pode ser visualizada como um embate de partes igualitárias. Isso porque, a renda média do autor da ação trabalhista é intermediária-baixa: 90,1\% recebiam até $\mathrm{R} \$ 4$ mil, e deste número, $62,5 \%$ até $\mathrm{R} \$ 1.996,00$. A hipossuficiência é latente. Grande parte das causas trabalhistas é movida por empregados com baixos salários e instrução, alocados nos setores de serviços e vendedores do comércio (33\%) e trabalhadores da produção de bens e serviços industriais (27\%).

Curiosamente, a participação dos sindicatos no polo ativo das demandas cresceu em 2,6\% quando comparada com a de 2012. Antes importava em 1\%, e no ano de 2018 perfez 3,6\%. Mas, atualmente, sua presença foi verificada em açôes de cobrança da contribuição sindical, cuja obrigatoriedade foi suprimida pela Lei n⿳0 $13.467 / 2017$ (alteraçáo da redação dos arts. $45,578,579,582,583$ e 587 da CLT) e não em açóes de tutela dos direitos dos empregados. Tanto é que, em termos de patrocínio do autor trabalhador, o percentual do sindicato como representante caiu de 9,3\% em 2012 para 8,5\% em 2018. Segundo os sindicatos, tal taxa é imprescindível para sua atuação em prol da categoria representada. Por sua vez, na percepção dos defensores da reforma, a taxa é umas das fortalecedoras do anacronismo do sistema sindical que não representa efetivamente os trabalhadores brasileiros.

\subsection{0 acordado prevalece sobre o legislado: rescisão por comum acordo e homologação de acordos extrajudiciais}

Apurou-se que em $86 \%$ dos autos as rescisóes do contrato de trabalho foram involuntárias. Nesses casos, é comum que se discuta em juízo as verbas rescisórias. ${ }^{8}$ Os casos de comum acordo, por sua vez, foram $2,6 \%$.

8. De acordo com o estudo do Conselho Nacional de Justiça (CNJ), 52,01\% das novas ações tinham como tema demandado "rescisão do contrato de trabalho/verbas rescisórias" (CNJ, 2016). 
Cogita-se que esse pequeno percentual de rescisão por comum acordo pode indicar alguma tendência ao distrato e da homologação judicial de acordos de rescisão (arts. 484-A, 855-B, D e E) após a autorização legal da reforma trabalhista de 2017. Afinal, uma premissa da reforma é ampliar o negociado em detrimento do legislado. A convenção coletiva de trabalho (CCT) e o acordo coletivo de trabalho (ACT) passaram a ter prevalência sobre a legislação trabalhista exclusivamente nas hipóteses relacionadas no novo art. 611-A da CLT.

Além disso, retirou-se a obrigatoriedade de que a homologação se faça no sindicato ou no Ministério Público do Trabalho (MPT), minando, de certa forma, a assistência gratuita na rescisão, capaz de gerar maior segurança ao empregado do recebimento correto das verbas. Há enfraquecimento do princípio da norma mais favorável ao trabalhador, tendo em vista que a homologação da rescisão pelo sindicato, segundo a pesquisa, ocorreu em 30,5\% dos casos.

No que se refere aos métodos alternativos de solução de litígios, 70,6\% dos processos não informavam sobre prévio encaminhamento da disputa a algum método institucionalizado de conciliaçáo, que não a negociação bilateral informal. Disso, interpreta-se que: ou as partes não encaminharam, ou deixaram de registrar nos processos.

Daqueles processos que foram encaminhados, 34,8\% foram para o Centro Judiciário de Solução de Conflitos e Cidadania (CEJUSC), 21,7\% foram feitos na própria empresa, 21,7\%, nos sindicatos; e 17,4\%, em outro órgão do Poder Judiciário diverso do CEJUSC. Esse percentual de $21,7 \%$ resolvido na empresa pode ser um leve reflexo da reforma e demonstrar mais uma tendência de discussão de verbas trabalhistas por negociação entre patrão e empregado. Além disso, alerta a doutrina:

Conquanto a finalidade da norma esteja focada na segurança jurídica, na prática sua utilização deve ser vista com bastante prudência pelo magistrado, pois atualmente verifica-se com muita frequência a existência de lides simuladas (chamadas coloquialmente de "casadinhas"), criando-se uma suposta lide para que seja homologada em juízo, com a finalidade exclusiva de sedimentar as discussóes sobre a relação de trabalho, além de impor renúncias dos direitos do trabalhador (Correia e Miessa, 2018, p. 936).

Outro dado que pode reforçar a tendência de majoração de acordos e sua homologação judicial, é o de proporção dos ritos processuais. O rito ordinário em 2012 foi seguido por $58,7 \%$ dos processos e, em 2018, por 61,3\%. O rito sumaríssimo em 2012 estava na faixa dos 35,8\%, enquanto caiu em 2018 para 29,3\%. A homologação de acordo extrajudicial, que abarcava zero processo em 2012, aponta um percentual de 1,7\% em 2018.

As sentenças homologatórias de acordo aumentaram de 2012 para 2018. Nesse último ano ocorreram em $38,9 \%$ dos casos. A proporção de pretensôes acordadas com relação às requeridas está abaixo de $50 \%$, principalmente para 13 o e horas extras (13\% e $9 \%)$. As verbas de caráter indenizatório e compensatório, como multas, são mais presentes. 


\subsection{Pretensões}

Verificou-se um aumento da quantidade média de pretensóes por processo submetidas nas açôes individuais - de 6,9 em 2012 para 9,7 em 2018 - além de maior diversificação dos pedidos.

Entre as hipóteses da reforma estava a necessidade de coibir a denominada litigância aventureira, segundo a qual o autor pediria tudo quanto pudesse ainda que ciente de que não estivesse em seu direito e sem quantificar os valores com exatidão. A Justiça do Trabalho, na visão dos reformistas, era protecionista em demasia e provia pretensões irrestritamente. Essa é a justificativa para a alteração ocorrida no art. 840, $\$ 1^{\underline{0}}$ e $\$ 3^{\underline{0}}$ da CLT.

As pretensóes que tiveram a maior variação negativa de 2012 para 2018, com redução pela metade, foram relativas a salários, $13^{\mathrm{o}}$, férias e horas extras. As pretensões que mais apareceram foram Fundo de Garantia do Tempo de Serviço - FGTS (60\%) e multa de 40\% do FGTS (53\%). Nesse sentido, cabe lembrar que os artigos da CLT que tratam das horas extras sofreram diversas alteraçóes com a reforma. No art. $4^{\mathrm{o}}, \mathbb{\$} 2^{\mathrm{o}}$, suprimiu-se da contagem do tempo de serviço algumas situaçóes laborais específicas, até então computadas como horas extras. Essas supressóes podem reduzir custos ao empregador. Segundo o art. 59, a autorização para compensar horário de serviço passou de acordo escrito para acordo individual e de contrato coletivo para convenção e acordo coletivo.

$\mathrm{O}$ art. 59-B acrescentado dispóe que o não atendimento das exigências legais de compensação, mesmo em acordo tácito, não implica repetição do pagamento das horas extras se não ultrapassada a carga máxima semanal, devido apenas o adicional. O parágrafo único diz que a prestação de horas extras habituais não descaracteriza o acordo de compensaçáo e o banco de horas. Isso inviabiliza o acesso à justiça do trabalhador, pois prejudica a intenção de pedir eventuais valores rescisórios sobre os quais teriam direito com o término do contrato.

A reforma manteve como verbas salariais apenas as gratificaçóes legais e comissóes pagas pelo empregador. No entanto, retirou dessa categoria a ajuda de custo, auxílio-alimentação, diárias para viagem, prêmios e abonos. Em consequência, tais verbas não se incorporam ao contrato de trabalho e não constituem base para incidência de qualquer encargo trabalhista e previdenciário.

Os danos extrapatrimoniais genéricos, em 2018, ficaram na faixa de 36,7\%; em 2012 eram 18,4\% de pedidos. Além disso, foram acolhidos em mais sentenças: de 3,1\% em 2012 para $4,7 \%$ em 2018. Este acolhimento é muito ligado a acordos posteriormente homologados - de 2,3\% em 2012 para 11,9\% em 2018 de acolhimento nos acordos - e sua inclusão se deve a fins fiscais e previdenciários.

Pela interpretação dos dados, aparentemente a reforma não obteve êxito em reduzir a quantidade e a diversidade de pedidos dos empregados. No entanto, pode-se pressupor que, uma rigidez na quantificação dos valores é capaz de desestimular o trabalhador a exigir seus direitos, por haver dificuldade em sua determinação e até mesmo em virtude do temer eventual condenação sucumbencial nas situaçôes em que o valor condenado for menor que o valor pretendido, já que é parte fragilizada no sentido de possuir poucos recursos financeiros e desconhecer a lei. 
Ademais, as determinaçóes de aditamento da petição inicial ocorreram em 5,1\% dos casos. Desses, 32,1\% por não indicação dos valores dos pedidos. Aparentemente, esta nova regra não foi bem assimilada nas práticas de litigância.

\subsection{Perícias, custas processuais, sucumbência e honorários}

Produziu-se prova pericial em 12,4\% dos casos em 2012; o número subiu para 14\% em 2018. Esses dados afastam a hipótese de que os litigantes estejam deixando de usar a produçáo de prova pericial, devido ao estabelecido no art. 790-B da CLT, o qual tornou os custos periciais passíveis de cobrança daquele que seja beneficiário da justiça gratuita. Desse número, $64,9 \%$ foram perícias em segurança do trabalho e 31,1\% perícias médicas.

A imposição ao vencido dos ônus da sucumbência relativa à perícia pretende agir como uma barreira no sistema de acesso à justiça, na medida em que não é comum que o litigante esteja absolutamente certo de vencer, tendo em vista as incertezas do processo (Cappelletti e Garth, 1988, p. 16-17). Assim, alteraçóes processuais da nova lei, principalmente, relativas à sucumbência abrem "um adicional campo de incerteza e elevado risco econômico para o autor de qualquer ação trabalhista” (Delgado, 2017, p. 49).

Em 2018, houve condenações em custas em 90\% dos casos. As sucumbenciais específicas foram menos frequentes tanto para peritos como para advogados (33\%). Com a introdução do art. 791-A na CLT, os honorários advocatícios de sucumbência passaram a existir, de modo geral, no processo do trabalho.

Os autores pagaram os valores de custas e/ou honorários ao fim do processo em 55\% dos casos. Provavelmente em decorrência do alto número de acordos firmados, que estipulam pagamentos de custas pelo autor. Antes da reforma, as custas no acordo eram divididas igualmente, salvo estipulação diversa (art. 789, $\$ 3^{\mathrm{o}}$ ). A média das custas sucumbenciais dos autores foi de $\mathrm{R} \$ 1.290,84$. É alta ao se considerar que $62,5 \%$ dos autores ganham até $\mathrm{R} \$ 1.996,00$. Eles foram responsabilizados por honorários periciais em 48,5\% dos casos e os reclamados (empregadores) em 53\%. Não havendo créditos suficientes para que o sucumbente beneficiário da justiça gratuita arque com a condenação em honorários advocatícios, nem neste, nem em nenhum outro processo, a exigibilidade ficará sob condição suspensiva por dois anos (art. 791-A, $\$ 4^{\circ}$ ).

A concessão da justiça gratuita ocorreu em 79,1\% dos casos e foi requerida em 90,5\%. Ainda que a redaçáo do $₫ 3^{0}$ do art. 790 da CLT tenha sido alterada para estabelecer que faz jus à justiça gratuita aquele que comprovar insuficiência de recursos para o pagamento das custas do processo $\left(\$ 4^{\circ}\right)$, na prática foi pedida e concedida para autores trabalhadores que instruíram a petição com simples declaração de necessidade. Houve isenção de custas na sentença ao autor, inclusive empregador, em $87,9 \%$ dos casos em que fora condenado ao pagamento. Em resumo, a declaração de insuficiência econômica continua a ser presumida verdadeira (Correia e Miessa, 2018, p. 701). 
Além disso, a maior parte das reformas de sentença de primeiro grau incidia sobre condenações sucumbenciais $(60,5 \%)$ e sobre o benefício da justiça gratuita $(25,6 \%)$, tanto para conceder como para denegar.

\subsection{Audiências}

Segundo apurou a pesquisa, as audiências únicas ocorreram em apenas 51,3\% dos casos. Houve cisão ou designação de nova audiência em 47,1\% e remessa ao CEJUSC em 1,5\% dos processos. A reforma trouxe hipótese de suspensão do julgamento com nova audiência em caso de motivo relevante (art. 844, $\$ 1^{\circ}$ ), notou-se que nem sempre esse motivo é relevante ou vem justificado em ata. Há, neste caso, uma falta de obediência prática ao artigo.

\subsection{Tempo do trâmite processual}

No geral, o trâmite processual tem demorado menos tempo do que em 2012. Da propositura ao arquivamento (ou sentença, se não arquivado) contou-se em média 512 dias, contra 761 em 2012. Ressalta-se que a maior incidência de acordos vem tendo impacto positivo na redução do tempo médio de processamento da etapa de execução, muito embora este ainda se mantenha em padróes bastante elevados.

\section{CONCLUSÃO}

Assim, a Lei n⿳o 13.467/2017, ao reivindicar a paridade de relaçóes trabalhistas, o aumento de acordos, a atenuação da quantidade de processos na justiça e sua adequação à globalização, realizou alteraçóes legais materiais e processuais que tiveram efeitos, conforme a análise da pesquisa empírica: $i$ ) contrários às suas premissas iniciais; $i$ ) probantes das premissas iniciais; $i i i$ ) e até mesmo sem qualquer efeito nas práticas do Judiciário, seja por ostentarem mandamentos legais que vão de encontro às práticas reiteradas das varas do trabalho, carecendo de legitimidade no meio jurídico, seja por não encontrarem a realidade fática proposta inicialmente.

De modo geral, na perspectiva do acesso, o perfil homogêneo dos litigantes foi confirmado pela pesquisa, mas o argumento da paridade sustentado pela reforma trabalhista foi rebatido. Os dados revelaram um trabalhador nitidamente hipossuficiente, com baixos salários e instrução, de quem também foi retirada a representaçáo sindical e a tutela em processos de rescisão contratual, comprovadas pela queda das taxas de patrocínio sindical na Justiça do Trabalho, principalmente a partir da desobrigação da taxa de contribuição.

Quanto ao contrato de trabalho, pode-se perceber leve aumento de rescisóes por acordo comum, que é prática estimulada e legalizada pela reforma. Nesse contexto, o trabalhador e o Judiciário correm o risco de terem homologados acordos a partir de lides simuladas, o que não ajuda na diminuição do número de processos trabalhistas empreendidos e na eficiência da justiça trabalhista. 
No que tange às demandas, a tentativa de diminuir a pressuposta litigância aventureira parece um tanto quanto inócua, pois a pesquisa revelou aumento e diversificação de pretensôes por processos. Por sua vez, notou-se diminuição de pretensôes relativas asalários e horas extras, provavelmente refletindo as alteraçóes legislativas materiais que modificaram e retiraram possibilidades de requerer verbas desse gênero (como a autorização do banco de horas, de modos de compensação, alterações nos tipos de verbas que se incorporam ao salário). Importante destacar a situação dos pedidos e acolhimento - em sentenças e acordos - de danos extrapatrimoniais. Houve aumento sensível, provavelmente como estratégia dos empregadores para reduzir o pagamento de verbas fiscais e previdenciárias. Assim, ainda que não tenha ocorrido aparente reduçáo de pedidos e tenha aumentado sua diversidade, algumas das principais verbas requeridas foram afetadas e alguns direitos suprimidos.

Nesse mesmo sentido, a maior rigidez na especificação dos valores das verbas na inicial provocou efeitos práticos, de forma que grande parte dos pedidos de aditamento da inicial foram embasados na falta de atribuição de valores aos pedidos. Essa exigência pode amedrontar o autor da ação, pois, se ele precisar os valores de forma incorreta, uma eventual improcedência de sua demanda poderá gerar valor sucumbencial muito alto.

Em sentido contrário, não parece ter ocorrido intimidação da nova lei perante os pedidos de perícia, os quais aumentaram. Disso decorrem duas hipóteses: ou são raros os pedidos despropositados, portanto, quem requer perícia está certo de sua demanda, ou os demandantes consideram imprescindível a realização desse tipo de prova, e, mesmo temendo a sucumbência, preferem apoiar-se no seu direito constitucional de contraditório e ampla defesa.

Ainda em questão sucumbencial, o pagamento dos honorários advocatícios vem sendo aplicado e, em metade dos processos analisados, os autores arcaram com as custas. Isso se deu, provavelmente, pela convenção de divisão proporcional de custas nos acordos. As médias de valores pagos a título de custas se mostraram altas perante o perfil da remuneração dos autores. Por seu turno, não se descartou a possibilidade recursal para revisão dessas cobranças, fundamentada no princípio in dubio pro misero. Nesse sentido, os dados demonstraram que a maior parte dos recursos tutelou a temática da sucumbência e da justiça gratuita.

Quanto a esta temática, percebe-se que há verdadeira falta de aplicabilidade prática da nova lei sobre as formas mais restritas de comprovação da hipossuficiência. Os magistrados, na maior parte, concederam a gratuidade da justiça a partir da mera manifestação do autor na inicial. Outra questão que aparenta carecer de legitimidade prática é a possibilidade de cisão das audiências. Além de o percentual de audiências cindidas ter sido alto, em diversas cisôes não restou explícito o motivo relevante que lhes deu causa.

Finalmente, entre as respostas ofertadas pelo Judiciário aos litigantes, novamente reforçase a tendência à homologação de acordos judiciais e extrajudiciais, prejudicando o acesso à justiça da parte trabalhadora com todas as garantias do devido processo legal. Ademais, nota-se que o trâmite processual em 2018 levou menos tempo em comparação ao trâmite de 2012, provavelmente pelo mesmo motivo elencado: a maior incidência de acordos reduz suavemente o tempo de processamento das lides no Judiciário trabalhista. 


\section{REFERÊNCIAS}

ANTUNES, T. C.; OLIVEIRA, L. J.; FERRER, W. M. H. A reforma da legislação trabalhista brasileira e o mito da hiperssuficiência do trabalhador em uma economia globalizada. Revista Jurídica Luso-Brasileira, Lisboa, v. 5, p. 2069-2088, 2019.

BRASIL. Câmara dos Deputados. Projeto de Lei no 6.787/2016. Altera o Decreto Lei no 5.452 , de $1^{\text {o }}$ de maio de 1943 - Consolidação das Leis do Trabalho, e a Lei no 6.019 , de 3 de janeiro de 1974, para dispor sobre eleiçóes de representantes dos trabalhadores no local de trabalho e sobre trabalho temporário, e dá outras providências. Diário Oficial da União, Brasília, 2016. Disponível em: <https://bit.ly/3jwQX6t>. Acesso em: 23 set. 2020. Texto Original.

Lei $\mathrm{n}^{\mathrm{o}} 13.467$, de 13 de julho de 2017. Altera a Consolidação das Leis do Trabalho (CLT), aprovada pelo Decreto-Lei $\mathrm{n}^{\mathbf{0}}$ 5.452, de $1^{\mathrm{o}}$ de maio de 1943 , e as Leis $\mathrm{n}^{\mathbf{0}}$ 6.019, de 3 de janeiro de 1974, no 8.036, de 11 de maio de 1990, e no 8.212, de 24 de julho de 1991, a fim de adequar a legislação às novas relaçôes de trabalho. Diário Oficial da Uniáo, Brasília, 2017. Disponível em: <https://bit.ly/3mp53IV>. Acesso em: 23 set. 2020.

CAPPELlETTI, M.; GARTH, B. Acesso à justiça. Porto Alegre: Fabris, 1988.

CNJ - CONSELHO NACIONAL DE JUSTIÇA. Justiça em números 2016: ano-base 2015. Brasília: CNJ, 2016.

CORREIA, H.; MIESSA, É. A reforma trabalhista e seus impactos. Salvador: JusPodivm, 2018.

DELGADO, M. G. A reforma trabalhista no Brasil: com os comentários a Lei nํㅗ 13.467/2017. São Paulo: LTr, 2017.

MARTINS FILHO, I. G. A necessidade de reformas para promover o bem comum da sociedade. Revista Consultor Jurídico, 1 ago. 2019. Disponível em: <https://bit.ly/3mkGyws>. Acesso em: 23 set. 2020.

KREIN, J. D. Balanço da Reforma Trabalhista do Governo FHC. In: PRONI, M. W.; HENRIQUE, W. (Orgs.). Trabalho, mercado e sociedade: o Brasil nos anos 90. São Paulo: Unesp, 2003, p. 279 a 321.

SANDEFUR, R. L. Access to justice: classical approaches and new directions. Access to justice: sociology of crime, law and deviance, v. 12, p. 9-17, 2009. Disponível em: <https:// bit.ly/31KHORP>. Acesso em: 23 set. 2020.

TIROLE, J. Economics for the common good. Princeton, Nova Jersey: Princeton University Press, 2017.

WEBER, M. O Direito na Economia e na Sociedade. São Paulo: Ícone, 2011.

\section{BIBLIOGRAFIA COMPLEMENTAR}

BRASIL. Decreto-lei no 5.452 , de 1ํㅡㄹ de maio de 1943. Aprova a Consolidação das Leis do Trabalho. Diário Oficial da Uniáo, Rio de Janeiro, 2 maio 1943. Disponível em: <https:// bit.ly/37E7tzn>. Acesso em: 23 set. 2020.

SANTOS FILHA, E. F. O acesso à justiça sob as perspectivas da reforma trabalhista. Revista Âmbito Jurídico, 22 jul. 2019. Disponível em: <https://bit.ly/2HBdZfj>. Acesso em: 23 set. 2020. 